\title{
Dual regulation of spine-specific and synapse-to-nucleus signaling by PKC $\delta$ during plasticity
}

Lesley A. Colgan\#, Paula Parra-Bueno, Heather L. Holman, Mariah F. Calubag, Jaime A. Misler, Xun Tu, Ryohei Yasuda ${ }^{\#}$

Neuronal Signal Transduction, Max Planck Florida Institute for Neuroscience, Jupiter, FL \# corresponding author: lesley.colgan@mpfi.org; ryohei yasuda@mpfi.org

\begin{abstract}
:
The activity-dependent plasticity of synapses is believed to be the cellular basis of learning. These synaptic changes are mediated through the coordination of local biochemical reactions in synapses and changes in gene transcription in the nucleus to modulate neuronal circuits and behavior. The protein kinase C (PKC) family of isozymes has long been established as critical for synaptic plasticity. However, due to a lack of suitable isozyme-specific tools, the role of the novel subfamily of PKC isozymes is largely unknown. Here, through the development of FLIM-FRET activity sensors, we investigate novel PKC isozymes in synaptic plasticity in mouse CA1 pyramidal neurons. We find that PKC $\delta$ is activated downstream of TrkB and that the spatiotemporal nature of its activation depends on the plasticity stimulation. In response to single spine plasticity, PKC $\delta$ is activated primarily in the stimulated spine and is required for local expression of plasticity. However, in response to multi-spine stimulation, a longlasting and spreading activation of PKC $\delta$ scales with the number of spines stimulated and, by regulating CREB activity, couples spine plasticity to transcription in the nucleus. Thus, PKC $\delta$ plays a dual functional role in facilitating synaptic plasticity.
\end{abstract}




\section{Introduction:}

Learning induces structural and functional changes in subsets of active spines to modulate neuronal circuits and behavior (Abdou et al., 2018; Gobbo \& Cattaneo, 2020; Hayashi-Takagi et al., 2015). These changes require early local plasticity of spines that is stabilized at later time points through gene transcription in the nucleus. The complex signaling cascades that mediate these changes, therefore, must transduce local and transient inputs ( $\mathrm{nm}$ and $\mathrm{ms}$ ) into long-lasting changes in cell-wide protein expression ( $\mathrm{mm}$ and hours). The coordination of early local events at spine heads and later changes that occur in the nucleus is not well understood, but kinase cascades, which can extend local, transient signals in both space and time have been implicated (Smolen et al., 2019).

One of the first kinase families identified to be essential for spine plasticity, learning and memory was the protein kinase C (PKC) family (Farley \& Auerbach, 1986; Hu et al., 1987; Malenka et al., 1986; Olds et al., 1989). Consisting of more than 12 isozymes and grouped in three subfamilies, it is increasingly clear that different PKC isozymes play unique roles in plasticity. Even single isoforms, whose specificity of signaling is largely defined by their spatiotemporal patterns of activation (Mukherjee et al., 2016), likely have complex roles depending on the nature of the plasticity-inducing stimulus. This complexity, combined with limited existing tools to measure and distinguish PKC isozyme activity with high spatiotemporal resolution, has limited understanding of the processes by which plasticity is expressed and stabilized at the molecular level.

Recently, tools to study the classic subfamily of PKC isozymes in plasticity were developed to reveal an isozyme-specific role for PKC $\alpha$ in the plasticity of spines and heterosynaptic plasticity (Colgan et al., 2018). This isozyme was activated for seconds in single dendritic spines but was able to integrate signals with variable spatiotemporal domains to facilitate metaplasticity and learning. The atypical isozymes, on the other hand, such as PKM memory on the timescale of hours to days, although their requirement and mechanisms in memory maintenance remain unclear (Borodinova et al., 2017). The role of the novel subfamily of PKC isozymes in synaptic plasticity, however, remains largely unknown.

The novel PKC isozymes consist of four isozymes, three of which are expressed in the mammalian hippocampus (PKCD, PKCE, PKCn, Naik et al., 2000). Unlike the classic subfamily, novel PKC isozymes do not bind calcium and are primarily activated by binding lipids, particularly the diacylglycerol (DAG) lipid messenger (Steinberg et al., 2008). Here, through loss of function studies and the use of newly- 
developed, isozyme-specific sensors, we explore the functions of novel PKC isozymes (PKCס, PKCE, PKCn) in plasticity. We find that PKC $\delta$ is uniquely required for the induction of structural plasticity of dendritic spines. Further, we identify its activators and characterize a dual functional role of PKC $\delta$ in both local induction of spine plasticity and the stabilization of this plasticity through spine-to-nucleus signaling.

\section{Results:}

\section{$\mathrm{PKC} \delta$, but not $\mathrm{PKC} \varepsilon$ or $\mathrm{PKC} \eta$ activity, is required for excitatory synaptic potentiation}

To assess the potential role of novel PKC isozymes in synaptic plasticity, we performed loss of function studies in a robust model of synaptic potentiation and learning: structural plasticity (sLTP) of dendritic spines (Choi et al., 2018; Hayashi-Takagi et al., 2015; Matsuzaki et al., 2004). sLTP was induced through optical uncaging of glutamate $\left(30\right.$ pulses at $0.5 \mathrm{~Hz}$ ) in the presence of tetrodotoxin in a $\mathrm{Mg}^{+2}$ free aCSF. This allowed for the precise and robust induction of SLTP at a single dendritic spine of CA1 pyramidal neurons in the stratum radiatum of organotypic hippocampal brain slice. SLTP was measured as the change in volume of the stimulated spine. Consistent with previous literature (Harvey, Yasuda, et al., 2008; Matsuzaki et al., 2004), glutamate uncaging induced rapid growth in stimulated spines of wildtype mice. The growth decayed slightly over minutes but remained elevated compared to prestimulus spine size. These changes were both spine-specific and long-lasting. Spine plasticity was not impaired in CA1 neurons in slices prepared from PKCE or PKCn knockout (KO) mice (Figure 1A, B). However, PKC $\delta$ KO mice showed impaired induction and expression of spine plasticity (Figure 1C, D). Spine growth was reduced in the early phases of SLTP and by $30 \mathrm{~min}$ the volume of the stimulated spine returned to its prestimulus size. This deficit could be fully rescued by sparse, acute ( 24-48 h) overexpression of PKC $\delta$ GFP, indicating the deficit is due to a postsynaptic, cellular role of PKC $\delta$ and not due to developmental or circuit-level changes (Figure 1).

As sLTP has been shown to correlate strongly with functional plasticity (Matsuzaki et al., 2004), our results suggested that this structural deficit would be concomitant with deficits in functional, electrically-induced potentiation. To test this, electrophysiological long-term potentiation was induced in acute hippocampal slices made from PKCD KO or WT littermate animals. Field EPSPs were recorded in the stratum radiatum of the CA1 region before and after stimulation of Schaffer collaterals with a thetaburst stimulation protocol. While no significant differences were seen in basal synaptic transmission (Figure 2A), neurons lacking PKC $\delta$ had significantly impaired potentiation (Figure 2B, 2C). 
bioRxiv preprint doi: https://doi.org/10.1101/2021.09.17.460844; this version posted September 18, 2021. The copyright holder for this preprint (which was not certified by peer review) is the author/funder, who has granted bioRxiv a license to display the preprint in perpetuity. It is made available under aCC-BY-NC-ND 4.0 International license.

A

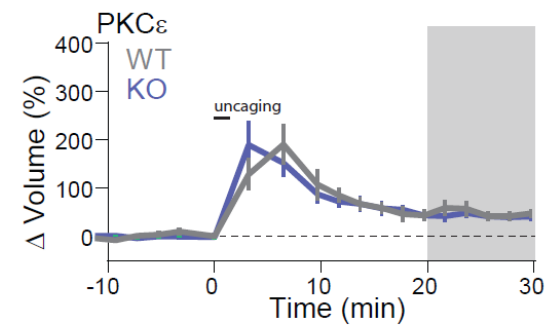

C

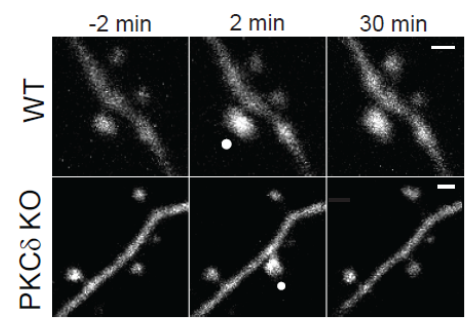

B

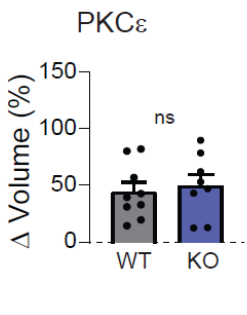

$\mathrm{PKC \eta}$

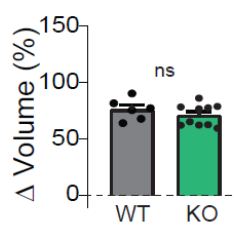

Figure 1: $\mathrm{PKC} \delta$, but not $\mathrm{PKC} \varepsilon$ or $\mathrm{PKCn}$, is required for structural plasticity

$A, B)$ Time course and quantification of glutamate uncaging induced change in volume of stimulated dendritic spines in hippocampal CA1 neurons from PKCE WT ( $n$ (spines/neurons $=9 / 6)$ or KO $(n=8 / 6)$ littermates (A) and PKCn WT $(n=6 / 5)$ or KO ( $n$ $=10 / 8$ ) littermates (B). Gray shading indicates the time of quantification of mean volume change (right). Two-way, unpaired $t-$ test non-significant $n s p>0.37$. C) Representative images of uncaging induced sLTP in neurons from PKC $\delta$ WT or KO littermates. The white dot indicates the location of uncaging. Scale bar $=1 \mu \mathrm{m}$. D) Time course and quantification of change in volume of stimulated spines from PKC $W T(n=12 / 6), K O(n=33 / 15)$, and KO neurons acutely overexpressing GFP-tagged PKC $(n=13 / 7)$. One-way ANOVA $[F(2,55)=16.85] p<0.0001$. Asterisks indicate Sidak's post-test comparing indicated groups, ${ }^{* * *} p<0.001$.

A

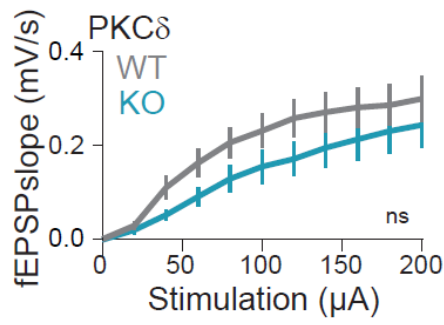

C

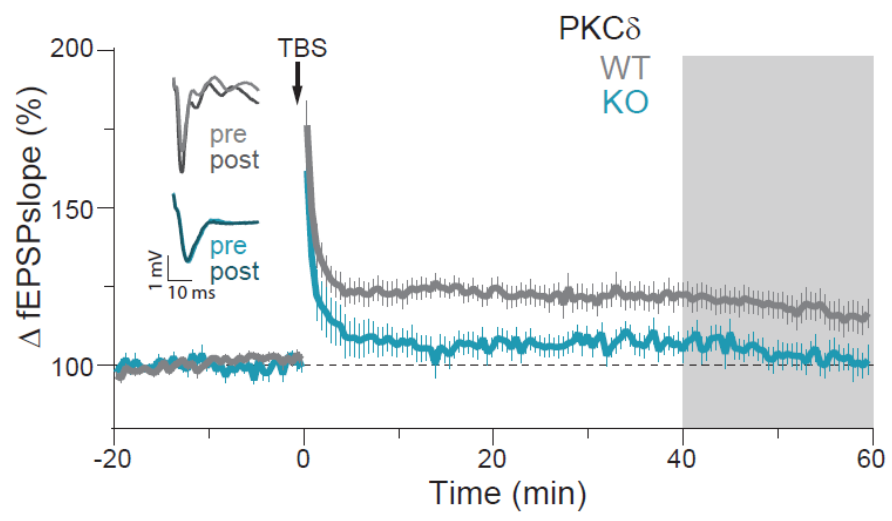

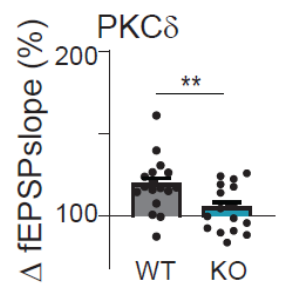

Figure 2: PKC is required for functional plasticity

A) Input-output curve of the field EPSP slopes between PKC $\delta$ WT and KO littermate mice. ns indicates results of repeated measures TwoWay Anova by genotype $[F(1,30)=1.829$, $p=0.19$ ] B, C) Quantification (B) and time course (C) of change in field EPSPs' slope in PKC $\delta$ WT $(n=17 / 8)$ and PKC $\delta$ KO $(n=16 / 4)$ CA1 hippocampal neurons after field stimulation of Schaffer collaterals with a $3 x$ or $5 x$ TBS stimulation protocol. Gray shading indicates the time of quantification in B. Insets (left) are the representative traces of field EPSP's before (pre) and after (post) stimulation from WT and KO slices. Asterisks indicate unpaired t-test, $* * \mathrm{p}=0.009$. 


\section{Development of isozyme specific sensors for novel PKC isoforms}

As this data demonstrated a critical role of PKC $\delta$ in structural and functional plasticity, we sought to investigate the spatial and temporal activity of PKC $\delta$ during plasticity. Therefore, we developed and

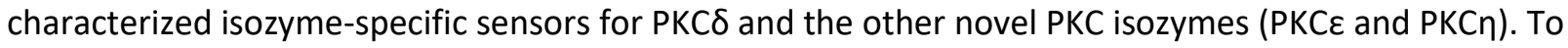
do this, we extended our previously developed and broadly applicable sensor design for the classic PKC isozymes (Colgan et al., 2018). This approach measures two aspects of PKC activation: (1) translocation of the kinase to the plasma membrane and (2) docking of a pseudosubstrate to the active kinase. These two approaches are named ITRACK (Isozyme-specific Translocation of C Kinase, Figure 3A top) and IDOCKS (Isozyme-specific Docking of C Kinase Substrate, Figure 3A bottom) respectively. ITRACK consists of the novel PKC of interest, N-terminally tagged with a FRET donor fluorophore, mEGFP, and expressed with a plasma membrane-targeted FRET acceptor fluorophore, mCherry. Upon activation of the PKC isozyme, translocation of the isozyme to membrane results in FRET between the donor and acceptor fluorophores. This increase in FRET is detected as a decrease in the fluorescence lifetime of the mEGFPtagged PKC isozyme. IDOCKS similarly consists of an mEGFP- tagged PKC isozyme expressed with an acceptor construct that consists of a pseudosubstrate sequence tagged with two mCherry fluorophores. Upon activation, the acceptor construct binds the active PKC isozyme, increasing FRET between the GFPtagged novel PKC and the acceptor construct. The activation of the novel PKC of interest, therefore, can be detected as a decrease in the fluorescence lifetime of the donor fluorophore. These designs provide a robust, isozyme-specific measurement of novel PKC activity.

ITRACK and IDOCKS were tested in cultured cells (Figure S1 A-D) and CA1 pyramidal neurons of organotypic hippocampal slices (Figure 3) by application of a strong pharmacological PKC activator $(\mathrm{PdBu}, 1 \mu \mathrm{M})$. For each of the novel isozymes, both ITRACK and IDOCKS showed significant changes in fluorescence lifetime upon phorbol ester application compared to vehicle application (Figure 3D, E). Importantly, control sensors, in which the acceptor was no longer targeted to the plasma membrane (ITRACK ${ }_{\text {CTL }}$ ) or in which the pseudosubstrate contained a single point mutation that disrupts binding to the PKC kinase site $\left(\right.$ IDOCKS $\left._{\mathrm{CTL}}\right)$, showed no significant lifetime changes in response to phorbol ester (Figure 3B, C, S1B). This suggests that the lifetime changes observed by ITRACK and IDOCKS reflect translocation of the novel PKCs to the membrane and binding of the novel PKCs to the pseudosubstrate, respectively. Our results suggest that these sensor approaches enable dynamic measurements of novel PKC activity in cells and neurons. 
bioRxiv preprint doi: https://doi.org/10.1101/2021.09.17.460844; this version posted September 18, 2021. The copyright holder for this preprint (which was not certified by peer review) is the author/funder, who has granted bioRxiv a license to display the preprint in perpetuity. It is made available under aCC-BY-NC-ND 4.0 International license.

A

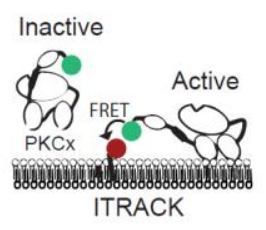

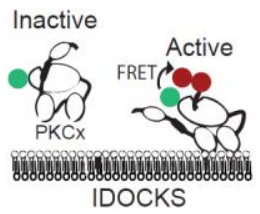

B
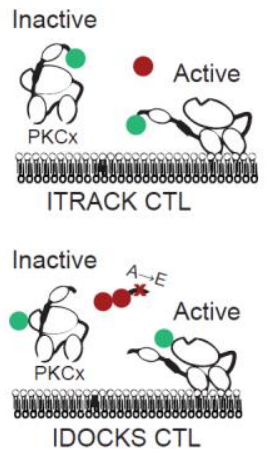

C
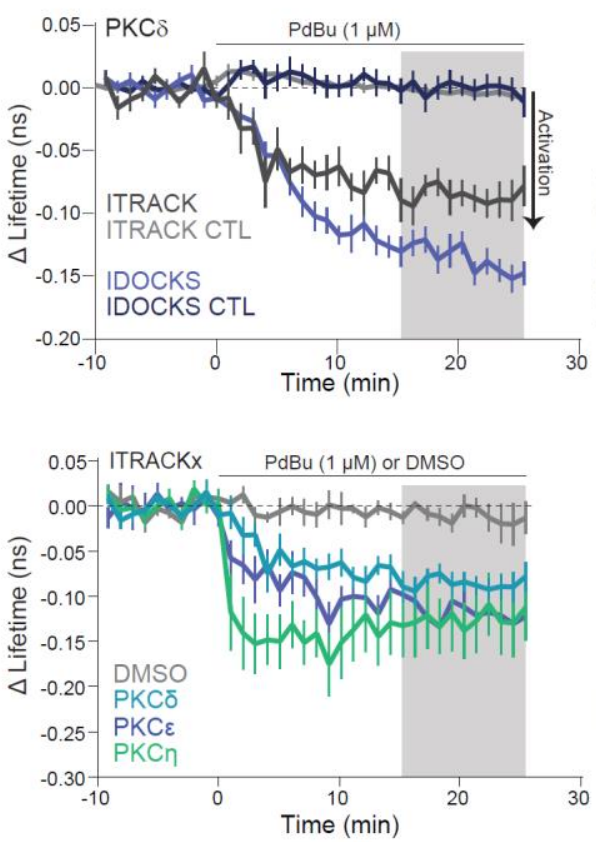

E

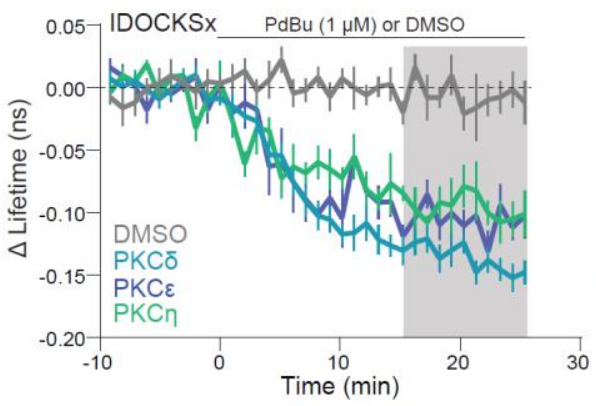

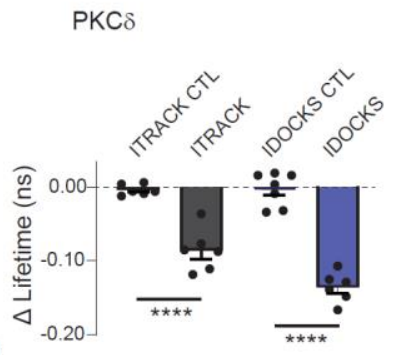
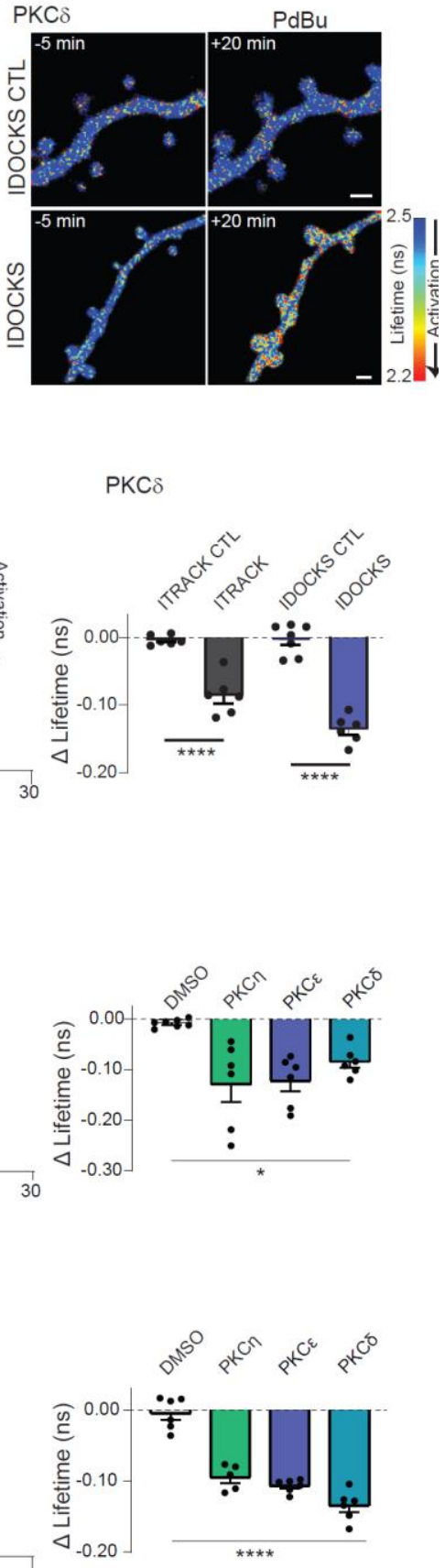

Figure 3: Characterization of FLIM-FRET sensors for novel PKC isozymes in neurons

A) Schematic of Isozyme-specific TRAnslocation of C- Kinase (ITRACK) and Isozyme-specific DOcking of CKinase Substrate (IDOCKS) sensors and respective control sensors (ITRACK CTL, IDOCKS CTL). B) Representative lifetime images of IDOCKS and IDOCKS CTL for PKCO in non-transgenic hippocampal CA1 neurons in response to PKC activation by phorbol ester $(1 \mu \mathrm{M}$ PdBu$)$. Warmer colors indicate lifetime decrease and sensor activation. C) Time course and quantification of mean change in the lifetime of ITRACK, IDOCKS, and CTL sensors for PKC $\delta$ in response to PdBu. Gray shading indicates the time over which average change was quantified (right). One Way ANOVA $[F(3,21)=$ 57.85] $\mathrm{p}<0.0001$, Asterisks indicate significance between indicated comparisons tested by Sidak's multiple comparison post-test $p<$ 0.001. $\mathrm{n} \geq 6$ neurons. $\mathrm{D}, \mathrm{E})$ Time course and quantification of the change in the lifetime of ITRACKX (D) or IDOCKSX (E) for $P K C \delta, P K C \varepsilon$, or $\mathrm{PKC}$, measured in hippocampal CA1 neurons in response to bath application of PKC activating drug $\mathrm{PdBu}$ or DMSO vehicle as indicated. Gray shading indicates the time over which the average change was quantified. One Way ANOVA $[F(3,19)$ $=54.98 \mathrm{p}<0.0001$, Asterisks indicate the lowest level of significance between each PdBu and vehicle group tested by Sidak's multiple comparison post-test. ${ }^{*} \mathrm{p}<0.05,{ }^{* * * *} \mathrm{p}<0.001, \mathrm{n} \geq$ 5. 


\section{PKC $\delta$ is activated in stimulated spines during plasticity induction}

Using our newly developed sensors, we measured the spatial and temporal activation pattern of PKC $\delta$ during the induction of single spine plasticity. To do this, we introduced IDOCKS $\delta$ into hippocampal CA1 neurons of organotypic slices from PKC $\delta$ KO animals and monitored sensor activation during uncaging-induced SLTP. During plasticity induction, there was a rapid decrease in the fluorescence lifetime of IDOCKS $\delta$ in the stimulated spine and, to a lesser extent, the underlying dendrite (Figure 4A). This activation of PKC $\delta$ peaked during uncaging in the stimulated spine ( $1 \mathrm{~min}$ ) and in the underlying dendrite with a slightly slower time course. Activation decayed by about $70 \%$ over the next several mins but did not return completely to baseline within the time imaged (Figure 4B). Importantly, control stimulations, in the absence of glutamate, or when NMDA receptors were blocked, did not induce activation of PKCS (Figure 4C), suggesting that activation is induced downstream of NMDA receptors and is not an artifact of laser stimulation. Moreover, the volume change induced during SLTP was not significantly different in neurons expressing either of the two sensors (ITRACK $\delta$ or IDOCKS $\delta$ ) or GFPtagged PKC $\delta$, suggesting that sensor expression did not disrupt downstream PKC signaling (Figure S2A). Unlike the activation seen through IDOCKS $\delta$, ITRACK $\delta$, which measures translocation of PKC $\delta$ to the plasma membrane, was not activated during SLTP (Figure S2B, C). This was despite robust activation of ITRACKס in response to PdBu application in neurons (Figure 3D). This finding suggests that PKC $\delta$ is not translocating to KRas-CAAX targeted membrane structures during the induction of SLTP and suggests that the nature and location of PKC isozyme activation are highly dependent on the specific stimulation received.

\section{PKC $\delta$ is downstream of TrkB activation}

Novel PKC isozymes are primarily activated by the production and binding to the lipid second messenger DAG. Recently, increased DAG production during NMDA stimulation or the induction of sLTP was demonstrated (Codazzi, 2006; Colgan et al., 2018). While there could be multiple sources of stimulation-induced DAG production, one mechanism described to support spine plasticity has been through NMDA-dependent autocrine release of BDNF and subsequent activation of TrkB (Harward et al., 2016). As we already demonstrated the requirement of the NMDAR for PKC $\delta$ activation (Figure 4C), we tested if PKC $\delta$ was also downstream of TrkB activation. IDOCKS $\delta$ was therefore monitored in neurons that had been genetically modified to contain an analog-sensitive point mutation in TrkB (TrkB-AS). This mutation is a single-point mutation in the ATP binding pocket of TrkB. The mutation leaves its kinase 
bioRxiv preprint doi: https://doi.org/10.1101/2021.09.17.460844; this version posted September 18, 2021. The copyright holder for this preprint (which was not certified by peer review) is the author/funder, who has granted bioRxiv a license to display the preprint in perpetuity. It is made available under aCC-BY-NC-ND 4.0 International license.

activity unaltered, but renders it sensitive to inhibition by a synthetic ATP analog, NM-PP1 (Chen et al., 2005). In neurons containing the TrkB-AS mutation that were untreated, or treated only with vehicle, SLTP-induced spine growth and PKC $\delta$ activation were normal (Figure 4D, E, CTL). However, TrkB-AS containing neurons treated with the inhibitor NM-PP1 showed impaired PKC $\delta$ activation and spine volume change during SLTP (Figure 4D, E, NM-PP1). This demonstrates that TrkB is upstream of PKC $\delta$ activity during plasticity, suggesting that PKC $\delta$ can monitor levels of BDNF-mediated activation of TrkB to facilitate plasticity.

A

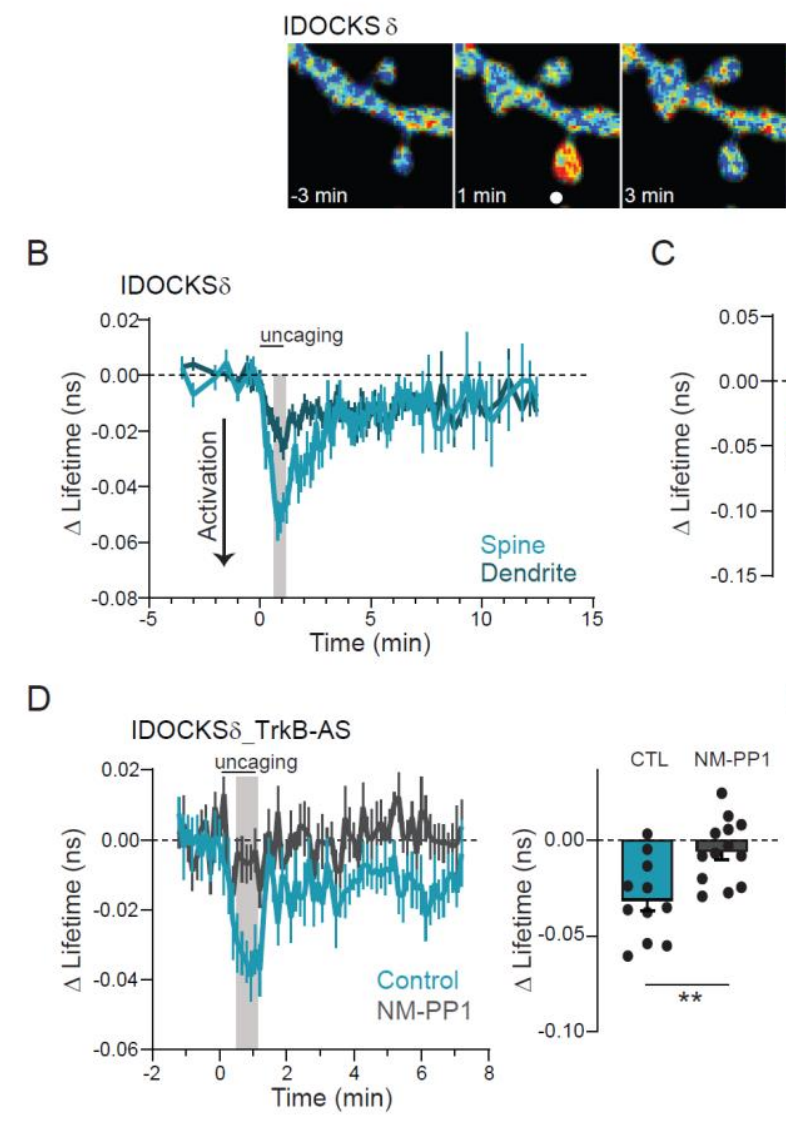

$E$

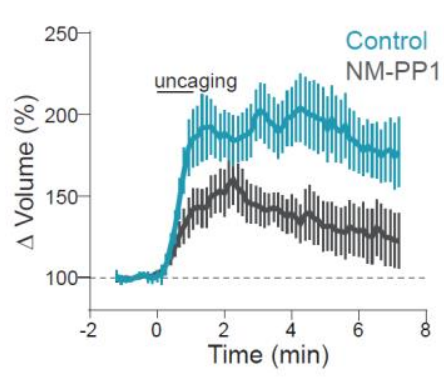

Figure 4: PKC $\delta$ is transiently activated in stimulated spines during plasticity A) Fluorescence lifetime images of IDOCKS in a single spine undergoing SLTP. The white dot indicates uncaging location. Scale bar $=1 \mu \mathrm{m}$. Warmer colors indicate shorter lifetimes and PKC $\delta$ activation. B) Mean time course of PKC $\delta$ activity in the stimulated spine and underlying dendrite measured by the change in the lifetime of IDOCKS during SLTP. $n$ (spines/neurons) $=26 / 10$. C) Quantification of mean lifetime change at the time indicated by gray shading in (B) and in response to uncaging stimulation in the absence of caged glutamate ( No Glu $n=17 / 9)$ or the presence of the NMDA-receptor antagonist APV $(50 \mu M, n=13 / 6)$. Two way ANOVA significant by treatment $[F(2,105)=32.96, p<0.0001]$, Asterisks indicate results of Sidak's multiple comparisons as indicated $(* * * * p<0.0001$, $* * * \mathrm{p}=0.0004$ ) D) The mean time course (left) and quantification (right) of PKC $\delta$ activity in stimulated spines in neurons containing an inert analog-sensitive mutation in TrkB-AS in the presence of vehicle (CTL, $n=11 / 5)$ or inhibitory ATP analog (NM-PP1, $1 \mu M n=$ 13/5). E) Time course of volume change of stimulated spines in D. 


\section{PKC $\delta$ activity is not restricted to stimulated spine}

During plasticity induction, the activation of PKC $\delta$ was highest in the stimulated spine, but was present at a lower level throughout the small region of dendrite imaged (Figure 4B), suggesting that PKC $\delta$ activity might be able to spread some distance from the synapse. Consistently, TrkB activation during plasticity has previously been reported to regulate long-distance signaling in neurons, including signals from synapses to the nucleus (Esvald et al., 2020; Harward et al., 2016; Moya-Alvarado \& Bronfman, 2020). Therefore, we hypothesized that TrkB activation of PKC $\delta$ might be a mechanism to extend local, transient signals in both space and time. To investigate whether PKC $\delta$ activity was able to spread over long distances, IDOCKS was monitored in the primary apical dendrite before and after inducing plasticity in a single dendritic spine or multiple spines spread across the dendritic tree (Figure $5 A)$. The induction of plasticity in multiple spines was previously shown to induce long-distance signaling to the nucleus of another kinase, the extracellular signal-regulated kinase (ERK) (Zhai et al., 2013). In response to plasticity in one spine, there was little activation of PKC $\delta$ in the primary dendrite. However, multiple spine stimulation (sequential induction of sLTP in 5 spines on 3 dendrites) led to a significant increase in PKC $\delta$ activity in the primary dendrite that was long-lasting (Figure 5B, C). To monitor the integration of multiple spine stimulation, $\mathrm{PKC} \delta$ activity was imaged in the primary dendrite during the sequential stimulation of 3 spines on different branches with longer time intervals between spine stimulations ( $8 \mathrm{~min}$ ). In response to this spaced stimulation of 3 spines, PKC $\delta$ activity integrated the stimuli in the primary dendrite to an intermediate level between the activation of 1 and 5 spines (Figure $5 D, E)$. This finding suggests that in addition to a local role in regulating plasticity in the spine, PKC $\delta$ may also play a long-distance signaling role in response to multiple spine plasticity.

To determine if the long-distance spreading of PKC $\delta$ activity was due to the directed translocation of PKC $\delta$ into the soma or nucleus, we monitored the somatic localization of GFP-tagged PKC (Figure 5F-H). Multi-spine stimulation did not induce significant somatic or nuclear translocation of PKC $\delta$ compared to mock stimulation and remained largely excluded from the nucleus. Thus, PKC $\delta$ does not show activitydependent translocation to the somatonuclear compartment but rather, is activated over long distances. 
bioRxiv preprint doi: https://doi.org/10.1101/2021.09.17.460844; this version posted September 18, 2021. The copyright holder for this preprint (which was not certified by peer review) is the author/funder, who has granted bioRxiv a license to display the preprint in perpetuity. It is made available under aCC-BY-NC-ND 4.0 International license.

A

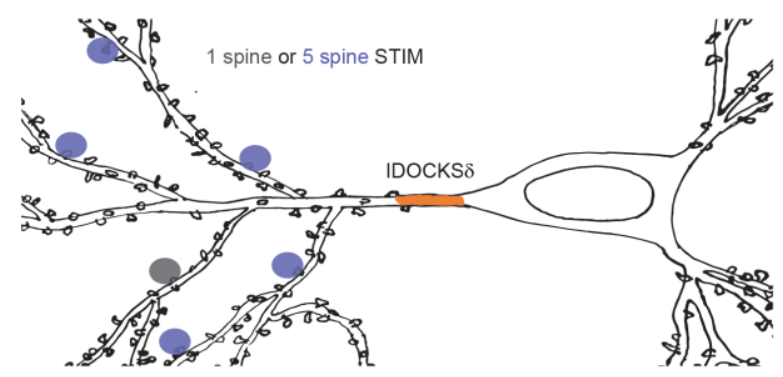

B

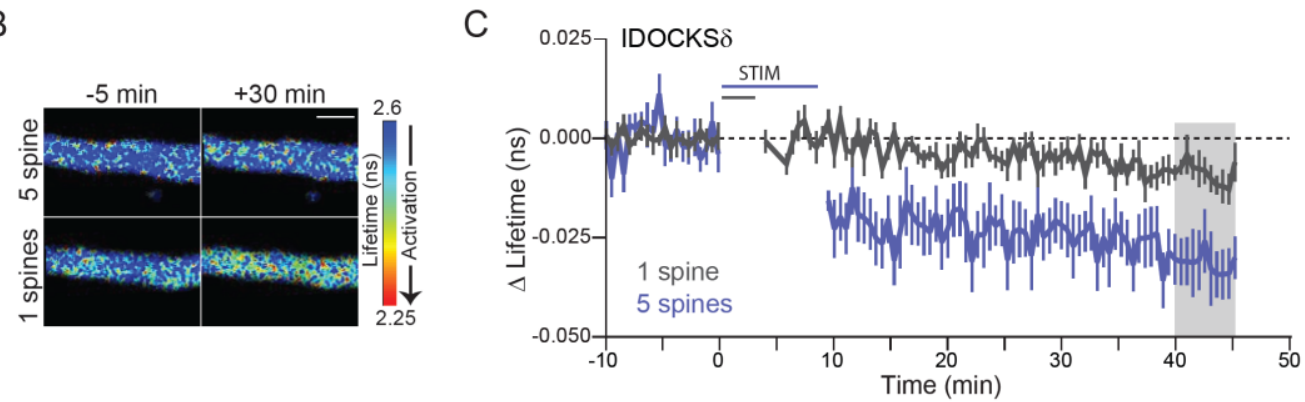

D

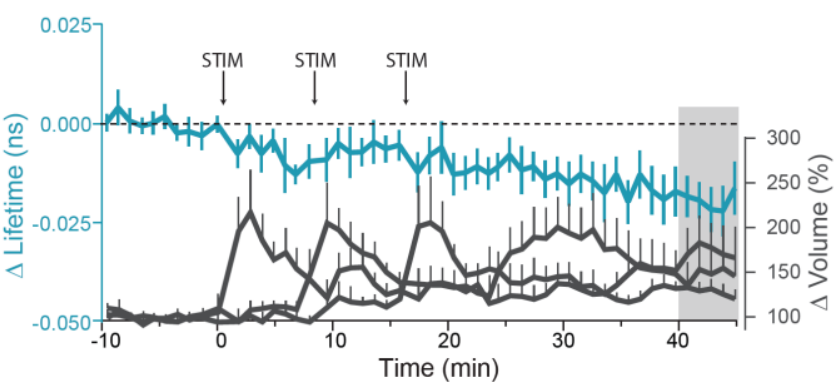

$\mathrm{E}$

$\mathrm{F}$

G

$\mathrm{H}$
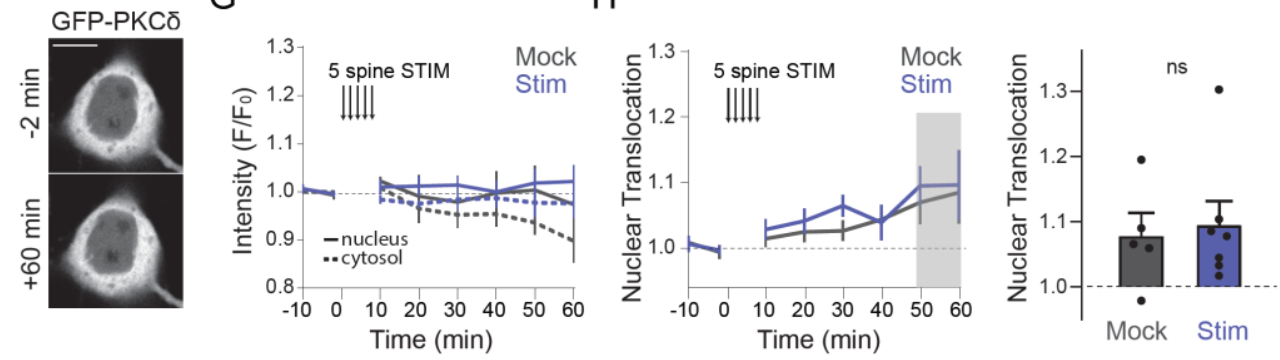

Figure 5: Multispine stimulation enhances long-lasting and spreading activation of PKC $\delta$ A) Schematic of 1 spine or 5 spine stimulation protocol. The gray area indicates the region where PKC $\delta$ activation was measured (primary dendrite). B) Representative lifetime images of IDOCKS $\delta$ in the primary dendrite in response to 1 or 5 spine stimulation. Warmer colors indicate decreased lifetime and activation of PKC $\delta$. Scale bar $=2 \mu \mathrm{m}$. C) Time course of PKC $\delta$ activity measured by the change in the lifetime of IDOCKS in response to induction of single spine SLTP ( $n$ (neurons) $=8$ ) or sequential induction of sLTP in 5 spines ( $n=13)$. D) Time course of PKC $\delta$ activation in the primary dendrite (left axis) during the spaced induction of 3 spines. The right axis shows the change in the volume of stimulated spines. $n$ (neurons)= 9. E) Quantification of mean change in the lifetime at 40-45 min (gray area in B) for 1 spine, 5 spines, or 3 spines stimulation $(n=9)$. Asterisks indicate results from a two-tailed unpaired t-test ${ }^{* *} p=0.0065$. F) Intensity images of GFP-PKC $\delta$ in hippocampal CA1 neurons before and 60 min after 5 spines stimulation. Scale bar $=10 \mu \mathrm{m} \mathrm{G}$ ) Time course of somatic cytosol and nuclear intensity (F/Fo) of GFP-PKC $\delta$ before and after 5 spine stimulation (Stim) or stimulation in the absence of caged Glu (Mock). H) Time course of nuclear translocation (Nuc intensity/Cytosol intensity). Gray shading indicates the time of quantification in H. H) Quantification of mean nuclear translocation after Stim or Mock in C. ns indicated results of unpaired two-tailed t-test. $p=0.7520$. 


\section{Acute and long-lasting PKC $\delta$ signaling have dual functions}

To investigate the potential functional role of this long-distance and long-lasting PKC $\delta$ activity further, we needed a tool to selectively inhibit long-lasting PKC $\delta$ activity. Due to a lack of isozymespecific PKC inhibitors, we replaced endogenous PKC $\delta$ with a previously characterized PKC $\delta$ mutant, PKCס-AS (Kumar et al., 2015). An analogous mutation to TrkB-AS, the PKC $\delta$-AS mutant consists of a point mutation that leaves its kinase activity unaltered but renders it sensitive to inhibition by a synthetic ATP analog, NM-PP1. Neurons expressing PKCD-AS in a PKC $\delta$ KO background and treated with vehicle showed normal SLTP. However, neurons treated with NM-PP1 shortly before the induction of SLTP showed impaired SLTP (-10 min, Figure 6). The return of spine size to pre-stimulus values at 20-30 min was consistent with the PKC $\delta$ KO plasticity phenotype and confirmed that PKC $\delta$ kinase activity is required for the spine plasticity. To determine whether sustained PKC $\delta$ activity was necessary for the maintenance of early phases of SLTP in the spine, we applied NM-PP1 $10 \mathrm{~min}$ after spine plasticity was induced. Blocking PKC $\delta$ kinase activity after plasticity induction, however, did not impair spine structural plasticity (+10 min, Figure $6 \mathrm{~B}, \mathrm{C})$. Therefore, unlike the early activity, long-lasting PKC $\delta$ activity is not required for the maintenance of early sLTP of dendritic spines.

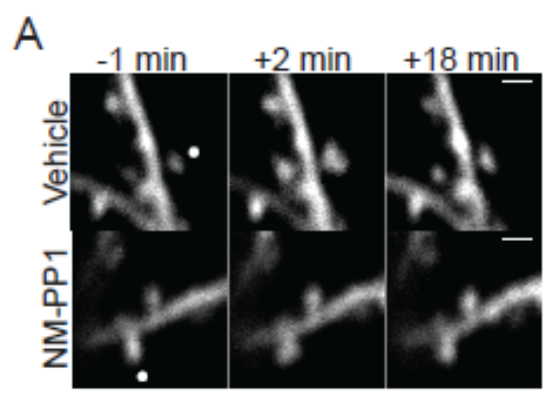

B
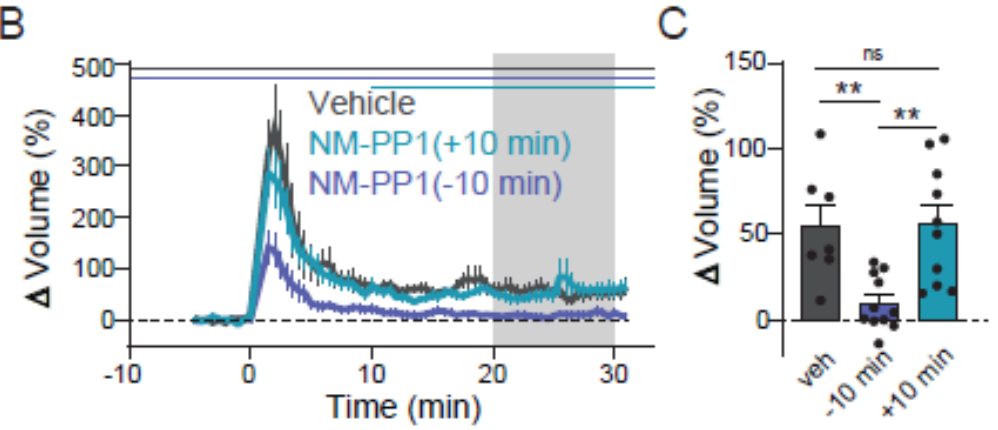

Figure 6: Acute but not long-lasting PKC $\delta$ kinase activity is required during plasticity of spines

A) Representative images of SLTP in neurons expressing PKC $\delta$ with an inert ATP binding pocket mutation (PKC $\delta$-AS) in place of PKC $\delta$. SLTP was induced in the presence of vehicle or the ATP analog (NM-PP1, $1 \mu \mathrm{M})$ to inhibit PKC $\delta$ kinase activity. The white dot indicates the location of uncaging. scale bar $=1 \mu \mathrm{m}$. B) Averaged time course of induced volume change of stimulated spines in the presence of vehicle $(n=7)$ or NM-PP1 applied 10 min before $(-10 \min , n=11)$ or 10 min after $(+10$ min, $n=10)$ uncaging stimulation. Gray shading indicates the time of quantification in C. C) Quantification of mean volume change. One way ANOVA $[F(2,25)=8.688]$. Asterisks indicate Sidak's multiple comparison post-test $* * p<0.0089, n s p=0.999$. 


\section{Long-lasting PKC $\delta$ activity is required for spine-to-nucleus signaling}

The ability of PKC $\delta$ to integrate the plasticity of multiple spines into a long-lasting and spreading signal suggested that it may regulate plasticity-dependent transcriptional programs, which are required for late phases of plasticity and memory formation (Alberini \& Kandel, 2015). Multi-spine stimulation was previously shown to induce long-lasting activation and nuclear translocation of ERK to regulate spine-to-nucleus signaling (Zhai et al., 2013). Interestingly, this signaling was found to be dependent on long-lasting PKC activity. Therefore, we tested whether ERK was a downstream target of long-lasting PKC $\delta$ activity. To do this, PKC $\delta$-AS was expressed in a PKC $\delta$ KO background to render it sensitive to inhibition and expressed together with a previously developed FLIM sensor for ERK activity (EKAR, Figure 7A) (Harvey, Ehrhardt, et al., 2008). We directly measured ERK activity in the primary dendrite of neurons during multi-spine stimulation. Consistent with previous data, ERK was activated in a longlasting manner (Figure 7B, C). However, applying NM-PP1 after the stimulation to inhibit long-lasting PKC $\delta$ activity, did not affect ERK activity in the primary dendrite, suggesting that ERK is not a downstream target of this phase of PKC $\delta$ activity.

A

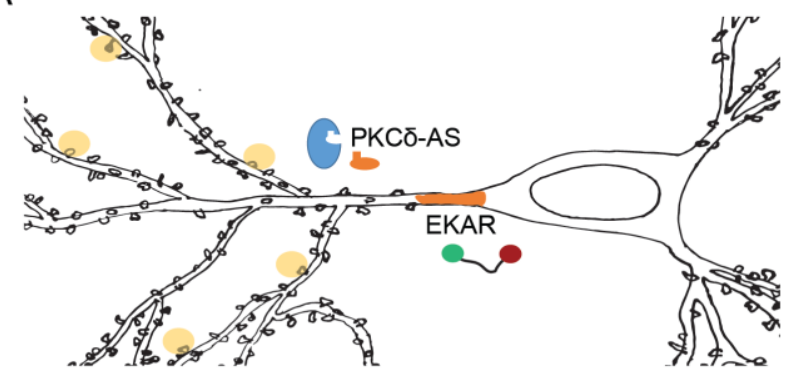

EKAR

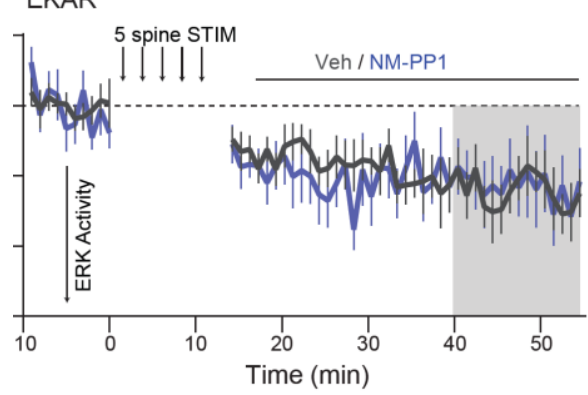

C

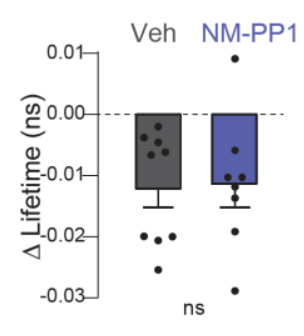

Figure 7: Long-lasting PKC $\delta$ activity does not regulate ERK

A) Schematic of experimental design B) The time course of ERK activity as measured by the mean change in the lifetime of the EKAR sensor in the primary dendrite after 5 spine stimulation. ERK activity was compared when either vehicle (n(neurons) $=9$ ) or NM-PP1 $(n=8)$ was added $10 \mathrm{~min}$ after the end of the stimulation to inhibit long-lasting PKC $\delta$ activity. C) Quantification of mean change in lifetime at the time indicated by gray shading in B. ns indicates the results of unpaired two-tailed t-test.

We, therefore, tested whether PKC $\delta$ might regulate plasticity-induced transcription independent of ERK. The activity-dependent transcription factor CAMP response-element binding protein (CREB) is activated by plasticity-inducing electrical protocols, as well as learning, and is required for the conversion of early to late phases of plasticity (Kandel, 2012). Moreover, PKC $\delta$ regulation of CREB has 
been demonstrated in-vitro and in other cellular contexts including in cardiac signaling (Garg et al., 2013; Ozgen et al., 2008; Yamamoto et al., 1988; Zhao, 2007). Therefore, we tested whether long-lasting PKC $\delta$ activity is involved in plasticity-induced, synapse-to-nucleus signaling to regulate CREB activity. To do this, PKC $\delta$-AS and a previously developed sensor for CREB were expressed in PKC $\delta$ KO neurons and SLTP was sequentially induced in 5 spines (Figure 8A, Laviv et al., 2020). After stimulation, NM-PP1, to inhibit long-lasting PKC $\delta$ activity, or vehicle was applied. Multi-spine stimulation led to robust activation of CREB in the nucleus that increased over tens of minutes (Figure 8B, C). However, inhibition of PKC $\delta$ with NM-PP1, significantly impaired CREB activation, which plateaued the time of inhibitor application (Figure 8B-D). This data suggests that PKC $\delta$ serves a dual functional role. In addition to facilitating local spine plasticity, PKC $\delta$ integrates multi-spine plasticity to regulate the magnitude of CREB activity in the nucleus, an efficient mechanism of spine-to-nucleus signaling.

A

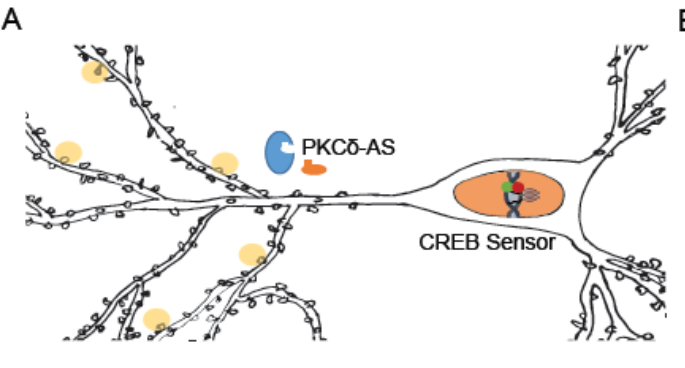

B

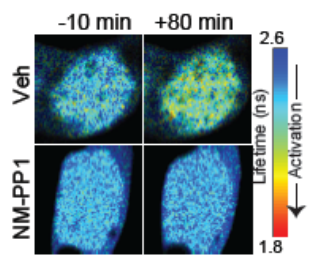

C

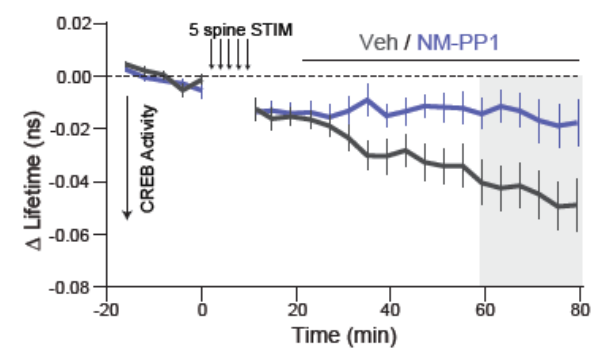

D

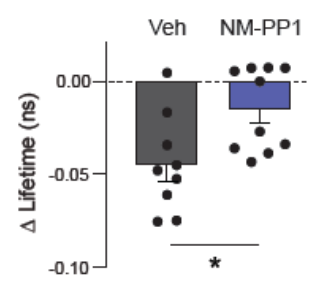

Figure 8: Long-lasting PKC $\delta$ activity regulates CREB activity

A) Schematic of five spine stimulation of CA1 neurons in which PKC $\delta$ was replaced by PKC $\delta$-AS. CREB activity was monitored in the nucleus using a CREB sensor. B, C, D) Representative lifetime images (B), time course (C) and quantification (D) of mean lifetime change of CREB sensor in the nucleus before after 5 spine stimulation and vehicle ( $\mathrm{n}=9$ neurons) or NM-PP1 $(1 \mu \mathrm{M}, \mathrm{n}$ $=10$ neurons) application $10 \mathrm{~min}$ after stimulation to inhibit long-lasting PKC $\delta$ activity. Gray shading indicates the time of quantification in D. Asterisk indicates results of two-tailed unpaired t-test $* p=0.016$

\section{Discussion:}

In this study, we have found that $\mathrm{PKC} \delta$, amongst the novel isozymes, is uniquely required for the induction of sLTP. Moreover, through the development of highly sensitive isozyme-specific biosensors, we have identified a dual functional role for $\operatorname{PKC} \delta$ that is defined by the spatiotemporal nature of its activation. During the plasticity of a single spine, NMDA-dependent TrkB activation leads to local PKC $\delta$ activity in the stimulated spine within $1 \mathrm{~min}$ that returns close to basal levels over approximately $5 \mathrm{~min}$. 
This early and local activation is essential for the induction of structural and functional spine plasticity. However, the induction of plasticity at multiple spines across the dendritic tree induces a long-lasting (>40 min) PKC $\delta$ activation that spreads throughout the neuron. This long-lasting activity scales with the number of stimulated spines to couple plasticity and transcription through the regulation of CREB in the nucleus. This dual functional role of PKC $\delta$ in plasticity is an efficient mechanism of coordinating the induction of plasticity in spines with protein synthesis in the nucleus required for long-term plasticity stabilization.

BDNF/TrkB signaling regulates the induction, expression, and consolidation of plasticity as well as learning (Figurov et al., 1996; Kang et al., 1997; Korte et al., 1995; Linnarsson et al., 1997; Minichiello et al., 1999; Mu et al., 1999). One mechanism of this regulation is through the activation of CREB-mediated transcription (Finkbeiner et al., 1997; Ying et al., 2002). This mechanism has often been hypothesized to occur through activation of the Ras/MAPK/ERK signaling (Impey et al., 1998; Ying et al., 2002; Zhai et al., 2013). Our study, however, implicates PKC $\delta$ in TrkB signaling to CREB and suggests that its regulation of CREB during plasticity induction is independent of ERK activity. This is consistent with previous work that generated phospho-site specific mutations in TrkB to study the role of specific downstream signaling cascades in plasticity (Minichiello et al., 2002). Animals with a mutation in the phosphosite that binds phospholipase C (PLC) to produce DAG and PKC signaling showed impaired expression and consolidation of LTP and reduced learning (Gruart et al., 2007; Minichiello et al., 2002). Moreover, these neurons showed impaired activation of CREB in response to BDNF application. These deficits were seen although ERK signaling remained intact. Together, the results implicate PKC $\delta$ as a necessary mediator of BDNFTrkB signaling to CREB during CA1 plasticity and hippocampal learning. These results also highlight the need for further understanding of plasticity-dependent transcriptional activation in response to various stimuli. Given the importance of these pathways in both physiology and disease, further study of this diversity of signaling as well as detailed signaling mechanisms through which PKC $\delta$ regulates CREB activity is warranted.

The development and characterization of isozyme-specific sensors for novel PKC activity will aid in the further study of the novel class of PKCs. Particularly in investigating the multiple roles of PKC isozymes that are specified by the spatiotemporal nature of their activation. The benefit of multiple sensor designs for protein activation was highlighted in this paper and also serves as a reminder for careful interpretation of sensor results. In this study, PKC $\delta$ activation measured by ITRACK $\delta$ and IDOCKS $\delta$ during sensor characterization showed similar activation profiles in response to a general PKC 
activating phorbol ester. However, in response to the induction of plasticity via glutamate uncaging, PKC $\delta$ activation was seen only with the IDOCKS $\delta$ sensor. The ITRACK sensor measures translocation of PKC isozymes to a membrane compartment that is labeled through targeting of a K-ras CAAX domain, which in neurons is primarily plasma membrane (Apolloni et al., 2000). This suggests that during induction of plasticity, PKC $\delta$ is active mostly at subcellular compartments that are not labeled by the ITRACK $\delta$ acceptor. Consistent with this finding, PKC $\delta$ has been shown to translocate to different subcellular domains, including the plasma membrane, the nuclear membrane, and the Golgi, depending on the nature of its activation (Wang et al., 1999), another mechanism to increase its diversity of signaling. Future work to probe PKC $\delta$ signaling at particular subcellular compartments, by modifying ITRACK $\delta$ to target the acceptor fluorophore to various locations, will help to clarify this diversity of signaling. As the novel subfamily of PKC isoforms has been implicated in numerous disorders, including metabolic disease, cardiovascular disease, autoimmune disorders, and disorders of neurodegeneration, these tools will be of great use for dissecting signaling pathways leading to cellular phenotypes in these diseases.

\section{Materials and Methods:}

DNA constructs: ITRACK: Donor plasmids using restriction site independent cloning were constructed into CMV-promotor containing mEGFP C1 vectors such that mEGFP was fused to the $\mathrm{N}$-terminus of PKC $\delta$ (mus musculus), PKCE (mus musculus), and PKCn (mus musculus). The acceptor plasmid, mCh-CAAX, consisted of mCherry followed by a 14 aa linker and a K-Ras derived lipid targeting motif (DGKKKKKKSKTKCVIM) driven by a CMV promoter. Negative controls for ITRACK (ITRACK CTL) consisted of the same donor construct and a control acceptor construct named mCh-CAAXneg in which a stop codon was introduced before the lipid targeting domain. IDOCKS: Donor plasmids consisted of PKC $\delta$, $\mathrm{PKC} \varepsilon$, and $\mathrm{PKC}$ which were tagged on their $\mathrm{C}$ termini with mEGFP driven by CMV promoter. The acceptor construct, $2 \mathrm{mCh}-\mathrm{PS}$, consisted of two copies of mCherry fluorophores separated by an eight amino acid linker followed by the 18 amino acid pseudosubstrate region from $\mathrm{PKC} \alpha / \beta$ (RFARKGALRQKNVHEVKN) driven by the CMV promoter. The negative control IDOCKS consisted of the same acceptor construct with a single point mutation $R \rightarrow E$ (RFARKGALEQKNVHEVKN). GFP-PKCD-AS was made through a single point mutation M425 to A in the donor construct of GFP tagged PKC (Kumar 
et al., 2015). CREB and EKAR sensors consisted of DNA constructs as previously described (Harvey, Ehrhardt, et al., 2008; Laviv et al., 2020).

HeLa cell maintenance, transfection and imaging: HeLa cells (ATCC CCL-2) were grown in Dulbecco's modified Eagle medium supplemented with $10 \%$ fetal bovine serum at $37^{\circ} \mathrm{C}$ in $5 \% \mathrm{CO}_{2}$. Plasmids were transfected into HeLa cells using Lipofectamine 2000 (Invitrogen) at a ratio of donor plasmid to acceptor plasmid of 1:3 for ITRACK and 1:2 for IDOCKS. Imaging was performed 24-48h following transfection in a HEPES-buffered aCSF solution (20 mM HEPES pH 7.3, $130 \mathrm{mM} \mathrm{NaCl}, 2 \mathrm{mM} \mathrm{NaHCO}{ }_{3}, 25 \mathrm{mM}$ D-glucose, $2.5 \mathrm{mM} \mathrm{KCl}, 1.25 \mathrm{mM} \mathrm{NaH}_{2} \mathrm{PO}_{4}$ ) with $2 \mathrm{mM} \mathrm{CaCl}_{2}$ and $2 \mathrm{mM} \mathrm{MgCl}_{2}$ by $2 \mathrm{pFLIM}$ as described below. When indicated, cells were stimulated with $1 \mu \mathrm{M} \mathrm{PdBu}$ (Tocris) or DMSO (0.02\%) vehicle.

Nontransgenic and Transgenic Animals: All experimental procedures were approved by the Max Planck Florida Institute for Neuroscience Animal Care and Use Committee, following guidelines by the US National Institutes of Health. Either nontransgenic or transgenic P3-P8 mouse pups from both sexes were used for organotypic slices for imaging studies as indicated. P30-P50 mice of both sexes were used for acute slices for electrophysiological studies.

-Nontransgenic animals, C57BI/6N Crl, were received from Charles River Lab. These animals were used in Figures 3.

-PKCS KO mice 129X1/SvJ were obtained from Jaxson labs (JAX stock \#028055) and developed as described previously described (Chou et al., 2004). Mice were backcrossed to swiss webster mouse line (CRL CFW) to improve breeding efficiency, litter size and mothering characteristics. Mice were bred het $x$ het to generate $W T$ and $K O$ littermates. These animals were used for Figures $1 C, D, 2,4 A-C, 5-8, S 2$.

-PKC $\varepsilon$ KO mice B6.129S4-Prkcetm1Msg/J were obtained from Jackson Lab (Jax Stock \#004189) and were developed as previously described (Khasar et al., 1999). Mice were bred het $\mathrm{x}$ het to generate WT and KO littermates. These animals were used in Figure $1 \mathrm{~A}$.

-PKC eta KO mice B6.Cg-Prkchtm1.2Gasc/J were obtained from Jackson Lab (Jax Stock \#018988) and were developed as previously described (Fu et al., 2011). Mice were bred het $x$ het to generate WT and KO littermates. These animals were used in Figure 1B. 
- Double transgenic mice PKCסKO/TrkB-AS were generated by crossing PKC $\delta K O$ mice with TrkB-AS mutant mice (TrkB $\left.{ }^{\mathrm{F} 616 \mathrm{~A}} \mathrm{C} 57 \mathrm{bl} / 6\right)$. TrkB ${ }^{\mathrm{F} 616 \mathrm{~A}} \mathrm{C} 57 \mathrm{bl} / 6$ mutant mice were developed and provided by Dr. David Ginty as previously described (Chen et al., 2005). Breeding pairs were KO on one gene and Het on the other gene. These animals were used in Figure 4D, E.

Organotypic hippocampal slice cultures and transfection: Organotypic hippocampal slices were prepared from non-transgenic or transgenic postnatal 3-8 day old pups of both sexes as previously described (Stoppini et al., 1991). In brief, pups were deeply anesthetized by isofluorane and then euthanized by decapitation. After removing the brain, hippocampi were dissected and cut into $350 \mu \mathrm{m}$ thick coronal slices using a Mcllwain tissue chopper (Ted Pella, Inc). Slices were plated on hydrophilic PTFE membranes (Millicell, Millipore) and maintained at 37 degrees and a $5 \% \mathrm{CO}_{2}$ environment in culture medium (MEM medium (Life Technologies), 20\% horse serum, $1 \mathrm{mM}$ L-Glutamine, $1 \mathrm{mM} \mathrm{CaCl} 2,2 \mathrm{mM}$ $\mathrm{MgSO}_{4}, 12.9 \mathrm{mM}$ D-Glucose, 5.2mM NaHCO $3,30 \mathrm{mM}$ Hepes, $0.075 \%$ Ascorbic Acid, $1 \mu \mathrm{g} / \mathrm{ml}$ Insulin) placed beneath the membranes. The culture medium was exchanged every other day. Organotypic slices were transfected after 7-10 DIV with biolistic gene transfer (O'Brien \& Lummis, 2006) using $1.6 \mu \mathrm{m}$ gold beads $(8 \mathrm{mg}$ ) coated with plasmids containing DNA of interest in the following amounts. mEGFP: $15 \mu \mathrm{g}$,

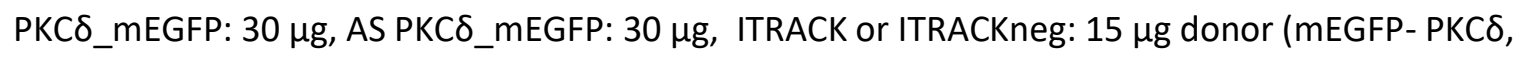
mEGFP-PKCE, or mEGFP-PKCn) and $40 \mu \mathrm{g}$ acceptor (mCh-CAAX or mCh-CAAX_neg), IDOCKS or IDOCKSneg: $10 \mu \mathrm{g}$ donor (PKC $\delta$-mEGFP, PKCE-mEGFP, or PKCn-mEGFP) and $20 \mu \mathrm{g}$ Acceptor (2mCh-PS or 2mCh-PSmut), GFP-PKC $\delta$-AS: $30 \mu \mathrm{g}$, GFP-PKC $\delta$-AS and CREB sensor: GFP-AS-PKC $\delta 15 \mu \mathrm{g}$ and $15 \mu \mathrm{g}$ donor (mEGFP-CREB) and $30 \mu \mathrm{g}$ acceptor (mCherry-KIX-mCherry), PKC - GFP: $30 \mu \mathrm{g}$, PKC $\delta$-AS and EKAR: $20 \mu \mathrm{g}$ each. Secondary or tertiary apical dendrites in the stratum radiatum of transfected CA1 pyramidal neurons were imaged 2-7 days after transfection by 2-photon microscopy or 2pFLIM as described below.

2-photon microscopy and 2pFLIM: PKC isozyme activity was measured using 2pFLIM. For quantification of spine volume change, we monitored the fluorescence intensity change of mEGFP in the spines using regular two-photon microscopy that was simultaneous with lifetime measurements. Intensity measurements and 2pFLIM imaging in HeLa cells and slices were performed using a custom $2 p$ microscope. mEGFP and mCh were excited with a Ti:sapphire laser (Chameleon, Coherent) at a wavelength of $920 \mathrm{~nm}$ and a power of 1.4-1.6 mW measured below the objective. The fluorescence was collected with an objective (60x, 1.0 n.a, Olympus), divided with a dichroic mirror (565 nm), and detected with two separated photoelectron multiplier tubes placed after wavelength filters (Chroma, 
510/70-2p for green and 620/90-2p for red). Photoelectron multiplier tubes with low transfer time spread (H7422-40p; Hamamatsu) were used for both red and green channels. The system was controlled via PCle 6323 and data is acquired by TimeHarp 260 pico dual (Picoquant). Software for data acquisition and analysis is FLIMage (Fluorescence Lifetime Imaging). FLIM images were taken at $64 \times 64$ or $128 \times 128$ resolution with 2, 6 or 12 frames averaged. Intensity images for analysis of SLTP volume change were collected by $128 \times 128$ pixels as a z stack of three slices with $1 \mu \mathrm{m}$ separation and averaging 6 frames/slice. Spine volume change was calculated as the background-subtracted $F-F_{0}$ where $F_{0}$ was the average fluorescence intensity before stimulation. In some cases of SLTP volume imaging of PKC KO neurons and WT littermates, parallel automated imaging of 2-3 spines per neuron was done using a custom-built interface in MATLAB by employing algorithms for autofocusing and drift correction to maintain position and focus (Smirnov et al., 2017). For these experiments, a 2 min stagger of uncaging events was incorporated to avoid data loss during uncaging events. Nuclear translocation was calculated from intensity measurements of the nucleus (nuc) and surrounding cytoplasmic fluorescence (cyt) in the central cross-section of the nucleus and calculated as the background-subtracted $\left[\mathrm{F}_{\text {nuc }} / \mathrm{Fo}_{\text {nuc }}\right] /\left[\mathrm{F}_{\text {cyt }} / \mathrm{Fo}_{\text {cyt }}\right]$, where Fo was the average fluorescence intensity before stimulation.

Two-photon glutamate uncaging: Structural plasticity of dendritic spines was stimulated through uncaging of 4-Methoxy-7-nitroindolinyl-caged-L-glutamate (MNI-caged glutamate, Tocris) using a Ti: Sapphire laser tuned at a wavelength of $720 \mathrm{~nm}$. The uncaging laser was focused to a small region $\sim 0.5$ $\mu \mathrm{m}$ from the spine and $2.7-2.9 \mathrm{~mW}$ of laser power (measured at the objective) was pulsed 30 times in a $0.5 \mathrm{~Hz}$ train with a $6 \mathrm{~ms}$ pulse width. Spines deeper than $50 \mu \mathrm{m}$ were not selected for uncaging experiments. Experiments were performed in $\mathrm{Mg}^{2+}$ fee artificial cerebral spinal fluid (ACSF; $127 \mathrm{mM}$

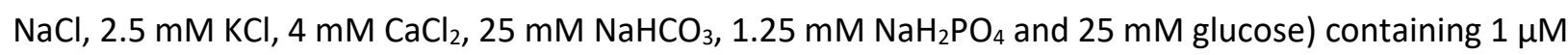
tetrodotoxin (TTX) and $4 \mathrm{mM} \mathrm{MNI}$-caged L-glutamate aerated with $95 \% \mathrm{O}_{2}$ and $5 \% \mathrm{CO}_{2}$. Experiments were performed at room temperature $\left(24-26^{\circ} \mathrm{C}\right)$. For multi-spine stimulation experiments, 5 spines were stimulated sequentially on 3-4 secondary or tertiary dendrites. Spines stimulated on the same dendritic branches were spaced by more than $25 \mu \mathrm{m}$.

2pFLIM analysis: To measure the change in fluorescence lifetime we fit a fluorescence lifetime curve summing all pixels over a whole image with a double exponential function convolved with the Gaussian pulse response function:

$F(t)=F_{0}\left[P_{D} H\left(t, t_{0}, \tau_{D}, \tau_{G}\right)+P_{A D} H\left(t, t_{0}, \tau_{A D}, \tau_{G}\right)\right]$ 
where $\tau_{A D}$ is the fluorescence lifetime of the donor bound with the acceptor, $P_{D}$ and $P_{A D}$ are the fraction of free donor and the donor undergoing FRET with the acceptor, respectively, and $H(t)$ is a fluorescence lifetime curve with a single exponential function convolved with the Gaussian pulse response function:

$H\left(t, t_{0}, t_{D}, t_{G}\right)=\frac{1}{2} \exp \left(\frac{\tau_{G}^{2}}{2 \tau_{D}^{2}}-\frac{t-t_{0}}{\tau_{i}}\right) \operatorname{erfc}\left(\frac{\tau_{G}^{2}-\tau_{D}\left(t-t_{0}\right)}{\sqrt{2} \tau_{D} \tau_{G}}\right)$

in which $\tau_{D}$ is the fluorescence lifetime of the free donor, $\tau_{G}$ is the width of the Gaussian pulse response function, $F_{0}$ is the peak fluorescence before convolution and $t_{0}$ is the time offset, and erfc is the complementary error function.

We fixed $\tau_{D}$ to $2.65 \mathrm{~ns}$ and $\tau_{\mathrm{AD}}$ to $1.33 \mathrm{~ns}$ based on previously published work of classic PKC isozyme sensors to obtain stable fitting (Colgan et al., 2018). To generate the fluorescence lifetime image, we calculated the mean photon arrival time, $\langle t\rangle$, in each pixel as:

$<t>=\int t F(t) d t / \int F(t) d t$,

Then the mean fluorescence lifetime, $\langle\tau\rangle$, is calculated as the mean photon arrival time minus an offset arrival time, $t_{o}$, which is obtained by fitting the whole image:

$<\tau>=\left\langle t>-t_{0}\right.$

Change in lifetime is calculated as mean fluorescence lifetime $<\tau>$ in ROI subtracted by the average lifetime in the ROI before stimulation.

The source code of the software is available online: https://github.com/ryoheiyasuda/FLIMage_public

Pharmacology: 1NM-PP1 (Santa Cruz, WD $1 \mu \mathrm{M}$ ), Phorbol 12,13-dibutyrate (PdBu, Tocris, WD $1 \mu \mathrm{M}$ ), MNI Caged Glu (Tocris, 4 mM), APV (Sigma, WD $50 \mu \mathrm{M}$ ) were stored as recommended by supplier and diluted into aCSF to the working dilutions (WD) listed.

Electrophysiology: Acute slice preparation: PKC $\delta$ WT or KO littermate mice (P30-P50) were sedated by isoflurane inhalation, and perfused intracardially with a chilled choline chloride solution. Brain was removed and placed in the same choline chloride solution composed of $124 \mathrm{mM}$ Choline Chloride, 2.5 $\mathrm{mM} \mathrm{KCl}, 26 \mathrm{mM}$ NaHCO3, 3.3 mM MgCl2, $1.2 \mathrm{mM} \mathrm{NaH2PO4,} 10 \mathrm{mM}$ Glucose and $0.5 \mathrm{mM} \mathrm{CaCl}$, pH 7.4 equilibrated with $95 \% 02 / 5 \% \mathrm{CO} 2$. Coronal slices $(300 \mu \mathrm{m})$ containing the hippocampus were cut using a vibratome (Leica) and maintained in a submerged chamber at $32{ }^{\circ} \mathrm{C}$ for $1 \mathrm{~h}$ and then at room 
temperature in oxygenated ACSF. Extracellular Recordings and LTP protocol: Slices were perfused with oxygenated ACSF containing $2 \mathrm{mM} \mathrm{CaCl} 2,2 \mathrm{mM} \mathrm{MgCl} 2$, and $100 \mu \mathrm{M}$ picrotoxin. One glass electrode (resistance $\sim 4 \mathrm{M} \Omega$ ) containing the same ACSF solution was placed in the dendritic layer of CA1 area ( 100-200 $\mu \mathrm{m}$ away from the soma) while stimulating Schaffer Collateral fibers with current square pulses $(0.1 \mathrm{~ms})$ using a concentric bipolar stimulation electrode (FHC). The initial slope of the fEPSP was monitored with custom software (MatLab). The stimulation strength was set to 50\% saturation. A 20 min stable baseline was first recorded before induction of LTP. LTP was induced by applying 3 to 5 trains of TBS stimulation. fEPSPs responses were recorded for an hour after the stimulation protocol. All data were analyzed with an in-house program written with Matlab.

Experimental Design and Statistical analysis: All values are presented as mean \pm SEM unless otherwise noted. The number of independent measurements $(n)$ is indicated in figure legends. For in-vitro studies, neurons were assigned to different groups to randomly interleave control and experimental groups from slices prepared from the same animals. Experiments from control and experimental groups were randomly interleaved during experimentation with the exception that each block of experiments began with one neuron from the control group to ensure the technical success of experiments. Data distribution was assumed to be normal but this was not formally tested. Unpaired two-tailed student's ttest was used for comparing two independent samples. One-way ANOVA followed by multiple comparison tests was used for comparing more than two independent samples. Two-way ANOVA followed by multiple comparison tests were used to compare grouped data sets. All t-tests and one-way ANOVAs included formal testing for differences in variance (e.g F test or Bartlett's test to compare variances) and appropriate corrections were made and are indicated in instances where this was relevant. Statistical tests and $p$ values are noted in each figure legend and were computed using GraphPad Prism 9 for Windows (GraphPad Software, La Jolla California USA, www.graphpad.com). For in-vitro experiments, data collection and analysis were not performed blind to the conditions of the experiments. Neurons in which there were obvious signs of poor health that developed during the experiment such as beading of processes were excluded before analysis. FLIM data in which there was more than 0.06 ns variation in the baseline (due to low photon number) were excluded from further analysis.

Competing Interests: Ryohei Yasuda is the owner of Florida Lifetime Imaging Ilc, a company which sells integrated solution for performing the highest quality fluorescence lifetime imaging (FLIM) and fluorescence resonance energy transfer (FRET) imaging. 
Acknowledgments: We would like to acknowledge David Kloetzer for lab management, Long Yan for microscopy development and maintenance, Yuki Hayano for technical assistance, Mary Philips for suggestions in figure design and the MPFI ARC, including Minida Dowdy, Elizabeth Garcia, and Amanda Coldwell for animal care and maintenance. This work was supported by National Institutes of Health Grants R35-NS-116804 (RY), R01-MH-080047 (RY), and F32MH101954 (L.A.C.).

\section{References:}

Abdou, K., Shehata, M., Choko, K., Nishizono, H., Matsuo, M., Muramatsu, S.-I., \& Inokuchi, K. (2018). Synapse-specific representation of the identity of overlapping memory engrams. Science (New York, N.Y.), 360(6394), 1227-1231. https://doi.org/10.1126/science.aat3810

Alberini, C. M., \& Kandel, E. R. (2015). The Regulation of Transcription in Memory Consolidation. Cold Spring Harbor Perspectives in Biology, 7(1), a021741. https://doi.org/10.1101/cshperspect.a021741

Apolloni, A., Prior, I. A., Lindsay, M., Parton, R. G., \& Hancock, J. F. (2000). H-ras but Not K-ras Traffics to the Plasma Membrane through the Exocytic Pathway. Molecular and Cellular Biology, 20(7), 2475-2487. https://doi.org/10.1128/MCB.20.7.2475-2487.2000

Borodinova, A. A., Zuzina, A. B., \& Balaban, P. M. (2017). Role of atypical protein kinases in maintenance of long-term memory and synaptic plasticity. Biochemistry (Moscow), 82(3), 243-256.

https://doi.org/10.1134/S0006297917030026

Chen, X., Ye, H., Kuruvilla, R., Ramanan, N., Scangos, K. W., Zhang, C., Johnson, N. M., England, P. M., Shokat, K. M., \& Ginty, D. D. (2005). A Chemical-Genetic Approach to Studying Neurotrophin Signaling. Neuron, 46(1), 13-21. https://doi.org/10.1016/j.neuron.2005.03.009

Choi, J.-H., Sim, S.-E., Kim, J., Choi, D. I., Oh, J., Ye, S., Lee, J., Kim, T., Ko, H.-G., Lim, C.-S., \& Kaang, B.-K. (2018). Interregional synaptic maps among engram cells underlie memory formation. Science, 360(6387), 430-435. https://doi.org/10.1126/science.aas9204

Chou, W.-H., Choi, D.-S., Zhang, H., Mu, D., McMahon, T., Kharazia, V. N., Lowell, C. A., Ferriero, D. M., \& Messing, R. O. (2004). Neutrophil protein kinase Cdelta as a mediator of stroke-reperfusion injury. The Journal of Clinical Investigation, 114(1), 49-56. https://doi.org/10.1172/JCI21655

Codazzi, F. (2006). Synergistic Control of Protein Kinase C Activity by lonotropic and Metabotropic Glutamate Receptor Inputs in Hippocampal Neurons. Journal of Neuroscience, 26(13), 3404-3411. https://doi.org/10.1523/JNEUROSCI.0478-06.2006

Colgan, L. A., Hu, M., Misler, J. A., Parra-Bueno, P., Moran, C. M., Leitges, M., \& Yasuda, R. (2018). PKC $\alpha$ integrates spatiotemporally distinct $\mathrm{Ca2}+$ and autocrine BDNF signaling to facilitate synaptic plasticity. Nature Neuroscience, 21(8), 1027-1037. https://doi.org/10.1038/s41593-018-0184-3 
DeVries, T. A., Neville, M. C., \& Reyland, M. E. (2002). Nuclear import of PKCdelta is required for apoptosis: Identification of a novel nuclear import sequence. The EMBO Journal, 21(22), 6050-6060. https://doi.org/10.1093/emboj/cdf606

Esvald, E.-E., Tuvikene, J., Sirp, A., Patil, S., Bramham, C. R., \& Timmusk, T. (2020). CREB Family Transcription Factors Are Major Mediators of BDNF Transcriptional Autoregulation in Cortical Neurons. Journal of Neuroscience, 40(7), 1405-1426. https://doi.org/10.1523/JNEUROSCI.0367-19.2019

Farley, J., \& Auerbach, S. (1986). Protein kinase C activation induces conductance changes in Hermissenda photoreceptors like those seen in associative learning. Nature, 319(6050), 220-223. https://doi.org/10.1038/319220a0

Figurov, A., Pozzo-Miller, L. D., Olafsson, P., Wang, T., \& Lu, B. (1996). Regulation of synaptic responses to high-frequency stimulation and LTP by neurotrophins in the hippocampus. Nature, 381(6584), 706709. https://doi.org/10.1038/381706a0

Finkbeiner, S., Tavazoie, S. F., Maloratsky, A., Jacobs, K. M., Harris, K. M., \& Greenberg, M. E. (1997). CREB: A Major Mediator of Neuronal Neurotrophin Responses. Neuron, 19(5), 1031-1047. https://doi.org/10.1016/S0896-6273(00)80395-5

Fu, G., Hu, J., Niederberger-Magnenat, N., Rybakin, V., Casas, J., Yachi, P. P., Feldstein, S., Ma, B., Hoerter, J. A. H., Ampudia, J., Rigaud, S., Lambolez, F., Gavin, A. L., Sauer, K., Cheroutre, H., \& Gascoigne, N. R. J. (2011). Protein Kinase $C \eta$ is Required for T Cell Activation and Homeostatic Proliferation. Science Signaling, 4(202), ra84. https://doi.org/10.1126/scisignal.2002058

Garg, R., Caino, M. C., \& Kazanietz, M. G. (2013). Regulation of Transcriptional Networks by PKC Isozymes: Identification of c-Rel as a Key Transcription Factor for PKC-Regulated Genes. PLOS ONE, 8(6), e67319. https://doi.org/10.1371/journal.pone.0067319

Gobbo, F., \& Cattaneo, A. (2020). Neuronal Activity at Synapse Resolution: Reporters and Effectors for Synaptic Neuroscience. Frontiers in Molecular Neuroscience, 13, 184.

https://doi.org/10.3389/fnmol.2020.572312

Gruart, A., Sciarretta, C., Valenzuela-Harrington, M., Delgado-García, J. M., \& Minichiello, L. (2007). Mutation at the TrkB PLC $\gamma$-docking site affects hippocampal LTP and associative learning in conscious mice. Learning \& Memory, 14(1-2), 54-62. https://doi.org/10.1101/Im.428307

Harvey, C. D., Ehrhardt, A. G., Cellurale, C., Zhong, H., Yasuda, R., Davis, R. J., \& Svoboda, K. (2008). A genetically encoded fluorescent sensor of ERK activity. Proceedings of the National Academy of Sciences, 105(49), 19264-19269. https://doi.org/10.1073/pnas.0804598105

Harvey, C. D., Yasuda, R., Zhong, H., \& Svoboda, K. (2008). The Spread of Ras Activity Triggered by Activation of a Single Dendritic Spine. Science, 321(5885), 136-140.

https://doi.org/10.1126/science.1159675

Harward, S. C., Hedrick, N. G., Hall, C. E., Parra-Bueno, P., Milner, T. A., Pan, E., Laviv, T., Hempstead, B. L., Yasuda, R., \& McNamara, J. O. (2016). Autocrine BDNF-TrkB signalling within a single dendritic spine. Nature, 538(7623), 99-103. https://doi.org/10.1038/nature19766 
Hayashi-Takagi, A., Yagishita, S., Nakamura, M., Shirai, F., Wu, Y. I., Loshbaugh, A. L., Kuhlman, B., Hahn, K. M., \& Kasai, H. (2015). Labelling and optical erasure of synaptic memory traces in the motor cortex. Nature, 525(7569), 333-338. https://doi.org/10.1038/nature15257

Hu, G.-Y., Hvalby, Ø., Walaas, S. I., Albert, K. A., Skjeflo, P., Andersen, P., \& Greengard, P. (1987). Protein kinase $C$ injection into hippocampal pyramidal cells elicits features of long term potentiation. Nature, 328(6129), 426-429. https://doi.org/10.1038/328426a0

Impey, S., Obrietan, K., Wong, S. T., Poser, S., Yano, S., Wayman, G., Deloulme, J. C., Chan, G., \& Storm, D. R. (1998). Cross Talk between ERK and PKA Is Required for Ca2+ Stimulation of CREB-Dependent Transcription and ERK Nuclear Translocation. Neuron, 21(4), 869-883. https://doi.org/10.1016/S0896$6273(00) 80602-9$

Kandel, E. R. (2012). The molecular biology of memory: CAMP, PKA, CRE, CREB-1, CREB-2, and CPEB. Molecular Brain, 5(1), 14. https://doi.org/10.1186/1756-6606-5-14

Kang, H., Welcher, A. A., Shelton, D., \& Schuman, E. M. (1997). Neurotrophins and Time: Different Roles for TrkB Signaling in Hippocampal Long-Term Potentiation. Neuron, 19(3), 653-664.

https://doi.org/10.1016/S0896-6273(00)80378-5

Khasar, S. G., Lin, Y.-H., Martin, A., Dadgar, J., McMahon, T., Wang, D., Hundle, B., Aley, K. O., Isenberg, W., McCarter, G., Green, P. G., Hodge, C. W., Levine, J. D., \& Messing, R. O. (1999). A Novel Nociceptor Signaling Pathway Revealed in Protein Kinase C $\varepsilon$ Mutant Mice. Neuron, 24(1), 253-260. https://doi.org/10.1016/S0896-6273(00)80837-5

Korte, M., Carroll, P., Wolf, E., Brem, G., Thoenen, H., \& Bonhoeffer, T. (1995). Hippocampal long-term potentiation is impaired in mice lacking brain-derived neurotrophic factor. Proceedings of the National Academy of Sciences of the United States of America, 92(19), 8856-8860.

Kumar, V., Weng, Y.-C., Geldenhuys, W. J., Wang, D., Han, X., Messing, R. O., \& Chou, W.-H. (2015). Generation and Characterization of ATP Analog-specific Protein Kinase C $\delta^{*}$. Journal of Biological Chemistry, 290(4), 1936-1951. https://doi.org/10.1074/jbc.M114.598698

Laviv, T., Scholl, B., Parra-Bueno, P., Foote, B., Zhang, C., Yan, L., Hayano, Y., Chu, J., \& Yasuda, R. (2020). In Vivo Imaging of the Coupling between Neuronal and CREB Activity in the Mouse Brain. Neuron, 105(5), 799-812.e5. https://doi.org/10.1016/j.neuron.2019.11.028

Linnarsson, S., Björklund, A., \& Ernfors, P. (1997). Learning deficit in BDNF mutant mice. The European Journal of Neuroscience, 9(12), 2581-2587. https://doi.org/10.1111/j.1460-9568.1997.tb01687.x

Malenka, R. C., Madison, D. V., \& Nicoll, R. A. (1986). Potentiation of synaptic transmission in the hippocampus by phorbol esters. Nature, 321(6066), 175-177. https://doi.org/10.1038/321175a0

Matsuzaki, M., Honkura, N., Ellis-Davies, G. C. R., \& Kasai, H. (2004). Structural basis of long-term potentiation in single dendritic spines. Nature, 429(6993), 761-766.

https://doi.org/10.1038/nature02617

Minichiello, L., Calella, A. M., Medina, D. L., Bonhoeffer, T., Klein, R., \& Korte, M. (2002). Mechanism of TrkB-Mediated Hippocampal Long-Term Potentiation. Neuron, 36(1), 121-137.

https://doi.org/10.1016/S0896-6273(02)00942-X 
Minichiello, L., Korte, M., Wolfer, D., Kühn, R., Unsicker, K., Cestari, V., Rossi-Arnaud, C., Lipp, H. P., Bonhoeffer, T., \& Klein, R. (1999). Essential role for TrkB receptors in hippocampus-mediated learning. Neuron, 24(2), 401-414. https://doi.org/10.1016/s0896-6273(00)80853-3

Moya-Alvarado, G., \& Bronfman, F. C. (2020). BDNF/TrkB mediates long-distance dendritic growth by activating CREB/PI3K-mTOR-dependent translation in neuronal cell bodies (p. 2020.08.22.262923). https://doi.org/10.1101/2020.08.22.262923

Mu, J.-S., Li, W.-P., Yao, Z.-B., \& Zhou, X.-F. (1999). Deprivation of endogenous brain-derived neurotrophic factor results in impairment of spatial learning and memory in adult rats. Brain Research, 835(2), 259-265. https://doi.org/10.1016/S0006-8993(99)01592-9

Mukherjee, A., Roy, S., Saha, B., \& Mukherjee, D. (2016). Spatio-Temporal Regulation of PKC Isoforms Imparts Signaling Specificity. Frontiers in Immunology, 0. https://doi.org/10.3389/fimmu.2016.00045

Naik, M. U., Benedikz, E., Hernandez, I., Libien, J., Hrabe, J., Valsamis, M., Dow-Edwards, D., Osman, M., \& Sacktor, T. C. (2000). Distribution of protein kinase $M \zeta$ and the complete protein kinase $C$ isoform family in rat brain. Journal of Comparative Neurology, 426(2), 243-258. https://doi.org/10.1002/10969861(20001016)426:2<243::AID-CNE6>3.0.CO;2-8

O'Brien, J. A., \& Lummis, S. C. R. (2006). Biolistic transfection of neuronal cultures using a hand-held gene gun. Nature Protocols, 1(2), 977-981. https://doi.org/10.1038/nprot.2006.145

Olds, J. L., Anderson, M. L., McPhie, D. L., Staten, L. D., \& Alkon, D. L. (1989). Imaging of memory-specific changes in the distribution of protein kinase $C$ in the hippocampus. Science, 245(4920), 866-869. https://doi.org/10.1126/science. 2772638

Ozgen, N., Obreztchikova, M., Guo, J., Elouardighi, H., Dorn, G. W., Wilson, B. A., \& Steinberg, S. F. (2008). Protein kinase D links Gq-coupled receptors to cAMP response element-binding protein (CREB)Ser133 phosphorylation in the heart. The Journal of Biological Chemistry, 283(25), 17009-17019. https://doi.org/10.1074/jbc.M709851200

Smirnov, M. S., Evans, P. R., Garrett, T. R., Yan, L., \& Yasuda, R. (2017). Automated Remote Focusing, Drift Correction, and Photostimulation to Evaluate Structural Plasticity in Dendritic Spines. PLOS ONE, 12(1), e0170586. https://doi.org/10.1371/journal.pone.0170586

Smolen, P., Baxter, D. A., \& Byrne, J. H. (2019). How can memories last for days, years, or a lifetime? Proposed mechanisms for maintaining synaptic potentiation and memory. Learning \& Memory, 26(5), 133-150. https://doi.org/10.1101/Im.049395.119

Steinberg, S. F. (2008). Structural Basis of Protein Kinase C Isoform Function. Physiological Reviews, 88(4), 1341-1378. https://doi.org/10.1152/physrev.00034.2007

Stoppini, L., Buchs, P. A., \& Muller, D. (1991). A simple method for organotypic cultures of nervous tissue. Journal of Neuroscience Methods, 37(2), 173-182. https://doi.org/10.1016/0165-0270(91)90128$\mathrm{m}$

Wang, Q. J., Bhattacharyya, D., Garfield, S., Nacro, K., Marquez, V. E., \& Blumberg, P. M. (1999). Differential Localization of Protein Kinase $C \delta$ by Phorbol Esters and Related Compounds Using a Fusion 
Protein with Green Fluorescent Protein*. Journal of Biological Chemistry, 274(52), 37233-37239. https://doi.org/10.1074/jbc.274.52.37233

Yamamoto, K. K., Gonzalez, G. A., Biggs, W. H., \& Montminy, M. R. (1988). Phosphorylation-induced binding and transcriptional efficacy of nuclear factor CREB. Nature, 334(6182), 494-498.

https://doi.org/10.1038/334494a0

Ying, S.-W., Futter, M., Rosenblum, K., Webber, M. J., Hunt, S. P., Bliss, T. V. P., \& Bramham, C. R. (2002). Brain-Derived Neurotrophic Factor Induces Long-Term Potentiation in Intact Adult Hippocampus: Requirement for ERK Activation Coupled to CREB and Upregulation of Arc Synthesis. Journal of Neuroscience, 22(5), 1532-1540. https://doi.org/10.1523/JNEUROSCI.22-05-01532.2002

Zhai, S., Ark, E. D., Parra-Bueno, P., \& Yasuda, R. (2013). Long-Distance Integration of Nuclear ERK Signaling Triggered by Activation of a Few Dendritic Spines. Science, 342(6162), 1107-1111. https://doi.org/10.1126/science.1245622

Zhao, D. (2007). Protein kinase Cdelta-mediated CREB activation regulates ghrelin-induced cyclooxygenase-2 expression and prostaglandin E2 production in human colonic epithelial cells. Journal of Cellular Biochemistry, 102(5), 1245-1255. https://doi.org/10.1002/jcb.21355

A

HeLa Cells

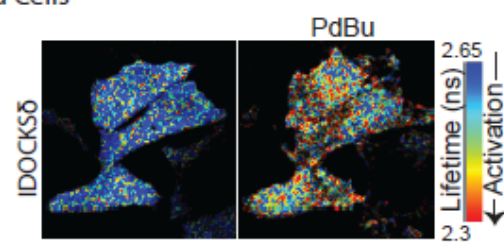

B

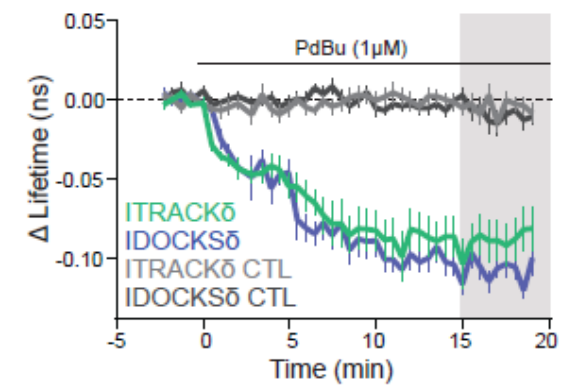

$\mathrm{C}$
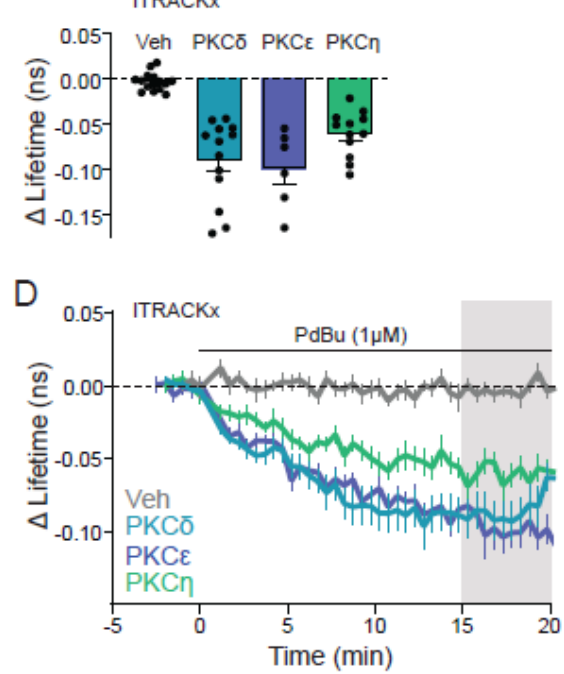

Figure S1: Characterization of novel PKC sensors in HeLa cells A) Representative lifetime images of IDOCKS in HeLa cells before and after PdBU $(1 \mu \mathrm{M})$ application. Warmer colors indicate a shorter lifetime and activation of PKC $\delta$. B) The time course of mean change in the lifetime of ITRACK $\delta$ ( $n$ (cells/experiments) $=13 / 4$ ) and IDOCKS $\delta(12 / 3)$ and control sensors in Hela cells in response to bath application of PdBU $(1 \mu \mathrm{M})$. C) Quantification of mean lifetime change of PKC $\delta, P K C \varepsilon$, or PKCn activity measured by ITRACK in response to PdBu or DMSO (Veh) as indicated. D) Time course of the data in C. 
bioRxiv preprint doi: https://doi.org/10.1101/2021.09.17.460844; this version posted September 18, 2021. The copyright holder for this preprint (which was not certified by peer review) is the author/funder, who has granted bioRxiv a license to display the preprint in perpetuity. It is made available under aCC-BY-NC-ND 4.0 International license.

Figure S2: IDOCKS $\delta$ but not ITRACK $\delta$ show PKC $\delta$ activation during SLTP

A) The volume change of stimulated spines of PKC $\delta$ KO neurons expressing ITRACK $\delta$, IDOCKS $\delta$, or PKC $\delta$. One way ANOVA ns $[\mathrm{F}(2,50)=1.933]$ $p=0.16$. B) Time course of volume change of stimulated spines in PKC $\delta$ KO neurons expressing IDOCKS $\delta$ or ITRACK $\delta$. C) Mean time course of PKC $\delta$ activity in the stimulated spine measured by the change in the lifetime of IDOCKS $\delta$ or ITRACK $\delta$ in response to induction of spine plasticity. D) Quantification of the mean change in the lifetime at 0.5 - 1 min (shaded region in C). Asterisks indicate results of an unpaired two-tailed t-test with Welch's correction for unequal variance $* * * * p<0.0001$.
A

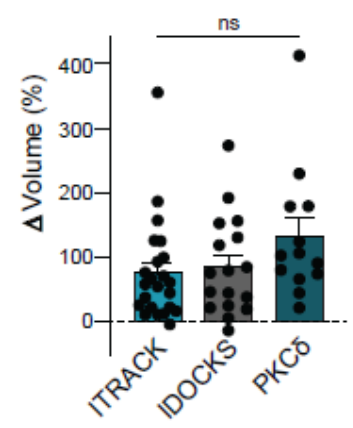

C

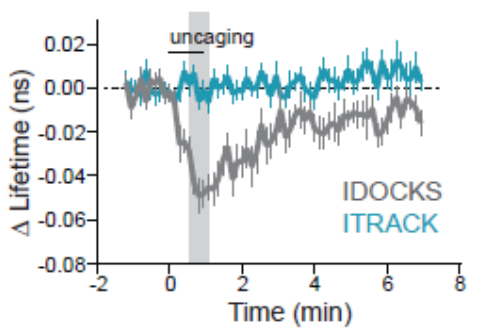

B
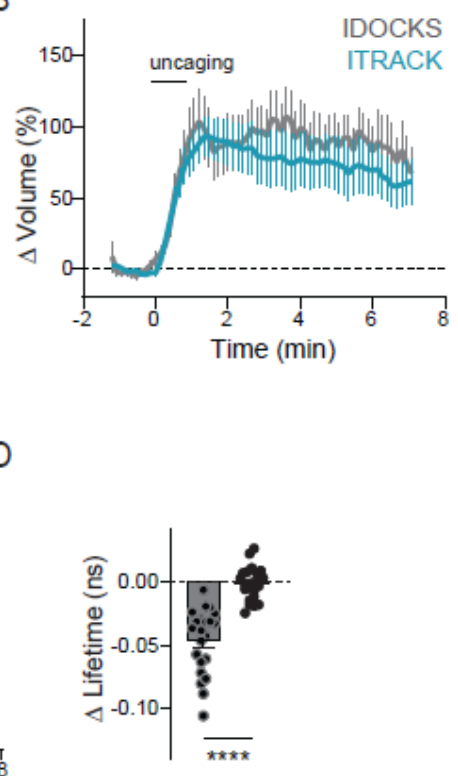